\title{
An optimal proportional integral derivative tuning for a magnetic levitation system using metamodeling approach
}

\author{
Abdualrhman Abdalhadi ${ }^{1}$, Herman Wahid ${ }^{1}$, Dirman Hanafi Burhanuddin ${ }^{2}$ \\ ${ }^{1}$ Control and Mechatronics Engineering Division, School of Electrical Engineering, Universiti Teknologi Malaysia, Johor, Malaysia \\ ${ }^{2}$ Faculty of Electrical and Electronic Engineering, Universiti Tun Hussein Onn Malaysia, Parit Raja, Malaysia
}

\begin{tabular}{l}
\hline Article Info \\
\hline Article history: \\
Received Jul 28, 2021 \\
Revised Dec 26, 2021 \\
Accepted Jan 17, 2022 \\
\hline
\end{tabular}

Keywords:

Magnetic levitation system Matlab

Optimal tuning

PID controller

Radial basis function network

\begin{abstract}
A magnetic levitation system (MLS) is a complex nonlinear system that requires an electromagnetic force to levitate an object in the air. The electromagnetic field is extremely sensitive to noise which can cause the acceleration on the spherical object, leading it to move into the unbalanced region. This paper presents a comparative assessment of controllers for the magnetic levitation system using proportional integral derivative (PID) controller based optimal tuning. The analysis was started by deriving the mathematical model followed by the implementation of radial basis function neural network (RBFNN) based metamodel. The optimal tuning of the PID controller has offered better transient responses with the improvement of overshoot and the rise time as compared to the standard optimization methods. It is more robust and tolerant as compared to gradient descent method. The simulation output using the radial basis based metamodel approach showed an overshoot of $9.34 \%$ and rise time of $9.84 \mathrm{~ms}$, which are better than the gradient descent (GD) and conventional PID methods. For the verification purpose, a Simscape model has been developed which mimic the real model. It was found that the model has produced about similar performance as what has been obtained from the Matlab simulation.
\end{abstract}

This is an open access article under the CC BY-SA license.

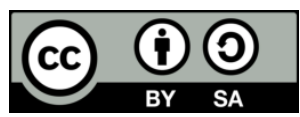

\section{Corresponding Author:}

Herman Wahid

School of Electrical Engineering, Faculty of Engineering, Universiti Teknologi Malaysia

81310 UTM Skudai, Johor, Malaysia

Email: herman@utm.my

\section{NOMENCLATURE}

Greek letters

$\begin{array}{ll}\eta & \text { Learning rate } \\ \alpha & \text { Momentum factor } \\ \mathrm{F} & \text { Force } \\ \mathrm{v} & \text { Velocity } \\ \mathrm{p} & \text { Power } \\ \mathrm{U} & \text { Stored Energy }\end{array}$

\section{INTRODUCTION}

For decades a \% was considered as a dream in science fiction, in 1726, Jonathan Swift described the magnetic levitation system (MLS) for the first time. Also, in 1842 an English clergyman called Samuel Earnshaw described the importance of maglev and its limitations. He showed that the system of maglev has instability issues, where the force between the static magnets and the contactless levitated part was impossible to be stable. The free levitated part has unstable displacement in at least one direction [1], [2]. 
Maglev has many applications in engineering field and industrial sector, such as in magnetic bearing systems, high-speed trains, vibration insulation systems, stepper photolithography, and wind turbine [3]. Recently, magnetic levitation systems have been appreciated for removing mechanical contact friction, to reduce maintenance costs and to achieve high-precision positioning. In 2010, a group of researchers from Rice University had developed a three-dimensional tumor model related to magnetic levitation. They have injected the cancer cells with magnetic iron oxide and gold nanoparticles. Moreover, by installing a coin size magnet near the infected area, they have successfully lifted the cells [4].

Electrodynamic suspension (EDS) and, electromagnetic suspension (EMS) are the two types of magnet levitation methods, as illustrated in Figure 1. "Repulsive levitation" is a term used to describe EDS systems. To supply comparable levitation sources, superconductivity magnets [5] or permanent magnets [6] are utilized. The magnetic levitation force provided by EDS is relatively steady and allows for a large clearance. However, as compared to the EMS method, the magnetic materials production process is more difficult and costlier. The EMS system referred to attractive levitation system. Since magnetic levitation force is inherently unstable, regulating the system is considerably more difficult than controlling the EDS system, and extra power is needed to maintain levitation height [7], [8].
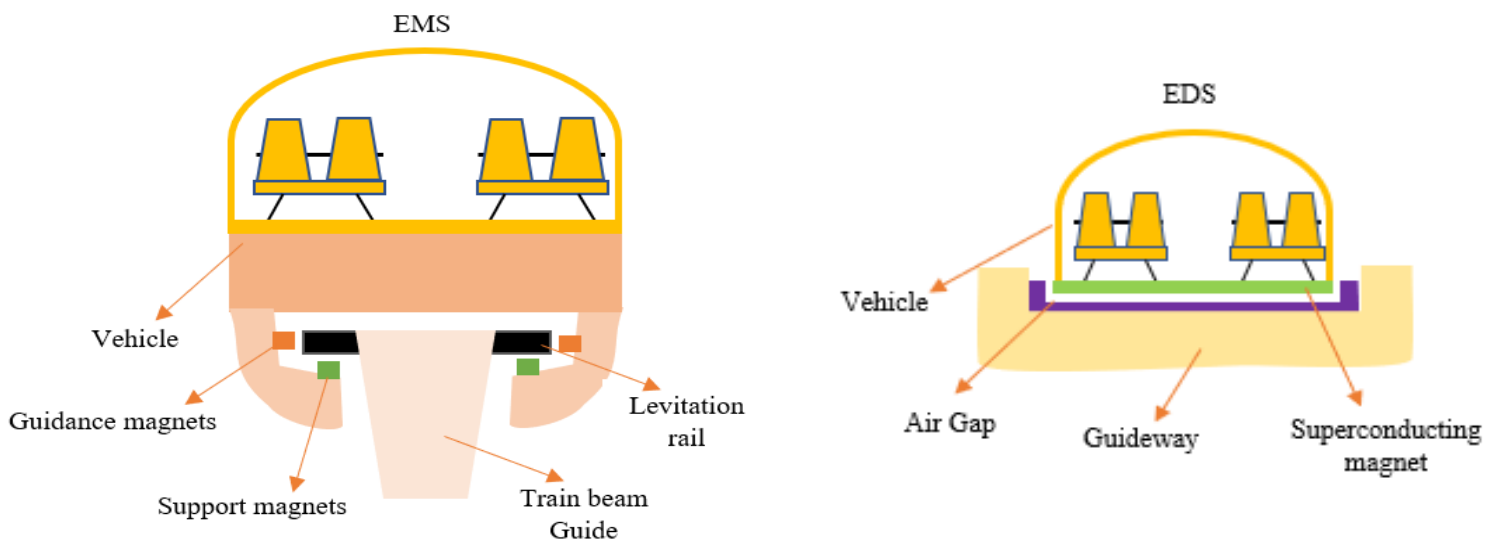

Figure 1. Attractive vs repulsive maglev system

Over the years, engineers and researchers have been paying great attention to stabilize the magnetic levitation system. The characteristic of the maglev system is extremely nonlinear. It is unstable and considerable as uncertainty. Proportional integral and derivative (PID) has been utilized to control the maglev system, which for so many years has been used in the industrial field. PID controllers have been utilized since the 1890s for controller design [9]-[12]. Until today the industrial field still uses PID controllers with other optimization techniques. The PID controllers could stabilize the maglev system, although the control performance of the system is limited due to the fixed controller parameters [13]-[16]. There are many optimal techniques that have been used to optimize PID parameter and one of these is neural network, and the increase of neurons may affect simulated response, because of the computation process. The metamodeling approach which will be explain in section 3, intended to reduce the computation process and time process, besides produce more efficint response. The research method will be presented in section 2, followed controller design in section 3 , result, and discussion in section 4 , and finally the paper conclusion in section 5 .

\section{METHOD}

Figure 2 shows the basic construction of the maglev system. Where the ferromagnetic ball is levitated in a controlled electromagnetic field [13]. The system comprises of a position sensor, electromagnetic actuator, optimal PID controller and a power supply circuit. The system's parameters used for this study are listed in Table 1. By studying the mechanical and mathematical modelling, behavior of the system can be modelled as in the following subsections. 


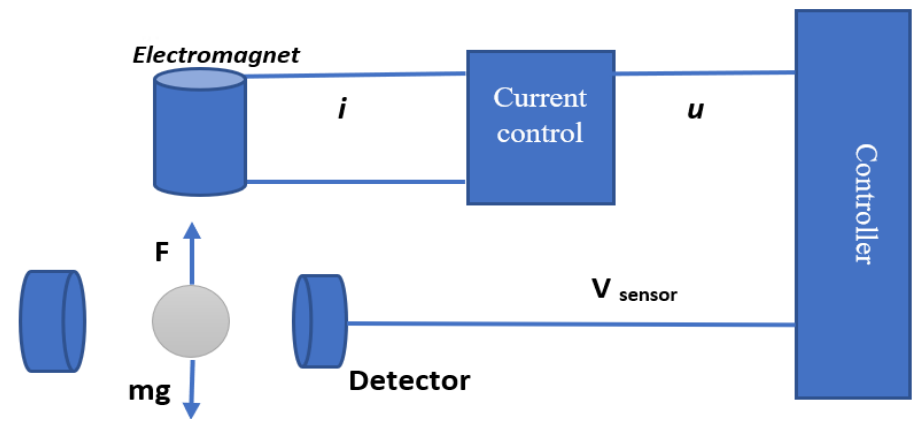

Figure 2. Magnetic levitation model

Table 1. Real parameters of maglev system

\begin{tabular}{ccc}
\hline Parameters & Values & Units \\
\hline $\mathrm{M}$ & 0.5 & $\mathrm{Kg}$ \\
$\mathrm{R}$ & 20 & $\mathrm{Ohm}(\Omega)$ \\
$\mathrm{L}$ & 0.158 & $\mathrm{H}$ \\
$\mathrm{g}$ & 9.8 & $\mathrm{~m} / \mathrm{sec}^{2}$ \\
$\mathrm{~K}$ & 0.08 & \\
$\mathrm{Y}$ & 0.03 & $\mathrm{~m}$ \\
$\mathrm{i}$ & 1.44 & $\mathrm{~A}$ \\
$\mathrm{~K}_{\mathrm{s}}$ & -458.7157 & \\
$\mathrm{~K}_{\mathrm{a}}$ & 5.8929 & \\
\hline
\end{tabular}

\subsection{Electrical equations of the MLS}

Magnetic levitation system consists of resistor and inductance, and with the current flow through the circuit, it produces a magnetic field, the energy needed to levitate the Ferro ball, thus, to calculate the energy stored inside the magnetic field will be as:

$$
\begin{aligned}
& p=i v \\
& v=l \frac{d i}{d t}
\end{aligned}
$$

the current starts at zero to steady-state at $\boldsymbol{I}$ final, will get:

$$
\begin{aligned}
& U=\int d U=L \int_{0}^{I_{f}} i d i \\
& U=\frac{1}{2} l I_{f}^{2}
\end{aligned}
$$

\subsection{Mechanical equations of the MLS}

By utilizing the Newton's third law of motion, and by ignoring the damping force and friction force of air [14], [15], the formula will be as (4) and (5):

$$
\begin{aligned}
& m \ddot{x}=m g-f\left(x_{B}, i_{c}\right) \\
& m \ddot{x}=m g-k \frac{i_{c}{ }^{2}}{x_{B}{ }^{2}}
\end{aligned}
$$

where: $m$ is the mass of the ball, $k$ is magnetic force constant, $x$ is ball position and $g$ is gravity constant.

\subsection{Transfer function model of the MLS}

The electromagnetic force $F(i, x)$ is nonlinear, and thus the MLS is a typical nonlinear system which requires linearization [16], as shown by (4) and (5). Linearization is achieved by utilizing Taylor's method to extend the nonlinear function. At the equilibrium point of $i_{0}$ and $x_{0}$, Taylor's theorem is applied to the maglev system in (5) will yield,

$$
F(i, x)=F\left(i_{0}, x_{0}\right)+\frac{\partial F_{i}(i, x)}{\partial i}\left(i-i_{0}\right)+\frac{\partial F_{x}(i, x)}{\partial x}\left(x-x_{0}\right)
$$


when the ball in maglev system in equilibrium condition the (4) and (5) will become:

$$
m g+F\left(i_{o}, x_{o}\right)=0 \& m g=-F\left(i_{o}, x_{o}\right)
$$

by defining the maglev system input will be the voltage to the inductor $\left(K_{a}\right)$, and the feedback from the plant will be the sensor gain $\left(K_{s}\right)$. By substituting the parameter's values from Table 1 will yield:

$$
G(s)=\frac{77.84}{0.031 s^{2}-30.53}
$$

Converting the transfer function in (8) to state space form will yield.

$$
A=\left[\begin{array}{cc}
0 & 1 \\
984.83 & 0
\end{array}\right], B=\left[\begin{array}{c}
0 \\
2511
\end{array}\right], C=\left[\begin{array}{ll}
0 & 1
\end{array}\right], D=[0]
$$

\subsection{PID controller based on ziegler nichols tuning}

PID known as "proportional-integral-derivative controller" is a linear controller and a typical method used in industrial application [17], [18]. PID controller is mathematically represented by:

$$
u(t)=K_{p} e(t)+K_{i} \int e(t) d t+K_{D} \frac{d e(t)}{d t}
$$

where $e(t)$ is the error. Ziegler Nichols based PID [19]. Equation is given as (11) and (12):

$$
\begin{aligned}
& \begin{aligned}
u(t) & =K_{p}\left(e(t)+\frac{1}{T_{i}} \int_{0}^{t} e(\tau) d \tau+T_{d} \frac{d e(t)}{d t}\right) \\
& =K_{p} e(t)+\frac{K_{p}}{T_{i}} \int_{0}^{t} e(\tau) d \tau+K_{p} T_{d} \frac{d e(t)}{d t}
\end{aligned} \\
& K_{d}=K_{p} T_{d}, K_{i}=\frac{K_{p}}{T_{i}}, K_{p}=0.6 \times K_{u}
\end{aligned}
$$

where, $K_{u}$ is the ultimate gain and $T_{d}$ and $T_{i}$ is the derivate time and integral time correspondingly.

\subsection{Radial basis function (RBF) with gradient descent PID tuning}

In the optimization studies, there is no definitive answer as to which model is better than the others. However, the Kriging model, Gaussian, and radial basis function are still the most often used methods [20]. The general radial basis function (RBF) equation is given as in (13):

$$
Y(k)=\sum_{j=1}^{N} w_{j} \varphi\left(\left\|X-C_{j}\right\|\right)
$$

where, $x \in R^{R \times 1}$ is an input vector, $\varphi$ is a basis function, $C_{j}$ is the RBF centres in the input vector space, $N$ is the number of hidden layer neurons, and $w_{j}$ is the weights in the output layer [21].

Gaussian function usually called Gaussian and used to arbitrary real constant and non-zero variable; it is simple and using it with the RBF network does not increase the computational complexity when using it with a significant variable or large dataset. where better analysis results can be obtained when executing the data set [22], [23]. The Gaussian function expressed as (14):

$$
h_{j}=\exp \exp \left[\frac{\left\|x-C_{j}\right\|^{2}}{2 b_{j}^{2}}\right], j=1,2, \ldots, m
$$

the weight of each vector is found as (15):

$$
W=\left[w_{j}\right]^{T}, j=1,2,3 \ldots N
$$

the identified RBF network output is:

$$
y_{m}(k)=\sum_{j=1}^{N} w_{j}(k) h_{j}(k)
$$

the identifier for performance cost function is: 
$J(k)=\frac{1}{2}\left(y(k)-y_{m}(k)\right)^{2}$

According to the network model chosen above, the iterative method is used to determine the updated weights, $\boldsymbol{w}$, biases, $\boldsymbol{b}$ and control, $\boldsymbol{c}$. to be calculated as:

$$
\begin{aligned}
& w_{j}(k)=w_{j}(k-1)+\eta\left(y(k)-y_{m}(k)\right) h_{j}(k)+\alpha\left(w_{j}(k-1)-w_{j}(k-2)\right) \\
& \Delta b_{j}(k)=\left(y(k)-y_{m}(k)\right) w_{j}(k) \frac{\left\|x-C_{j}\right\|^{2}}{2(k)^{3}} \\
& b_{j}(k)=b_{j}\left((k-1)+\eta \Delta b_{j}(k)\right) \alpha\left(b_{j}(k-1)-b_{j}(k-2)\right) \\
& \Delta b_{j i}(k)=\left(y(k)-y_{m}(k)\right) w_{j}(k) \frac{x_{j}(k)-c_{j i}(k)}{b_{j}(k)^{2}} \\
& c_{j i}(k)=c_{j i}\left((k-1)+\eta \Delta c_{j i}(k)\right) \alpha\left(c_{j i}(k-1)-c_{j i}(k-2)\right)
\end{aligned}
$$

where: $\eta$ is the learning rate and $\alpha$ is the momentum factor.

The Jacobian matrix is used to compare output values and evaluate the system's control sensitivity by executing the output and input of the controlled system in real-time [24], [25]. The Jacobian algorithm is provided as:

$$
\frac{\partial y(k)}{\partial \Delta u(k)} \approx \frac{\partial y_{m}(k)}{\partial \Delta u(k)}=\sum_{j=1}^{m} w_{j}(k) h_{j}(k) \frac{c_{j i}(k)}{b_{j}(k)^{2}}
$$

based on the algorithm of incremental PID to the control system is given as:

$$
e(k)=r(k)-y(k)
$$

the inputs of the PID controller are given as:

$$
\begin{aligned}
& x c_{1}=e(k)-e(k-1) \\
& x c_{2}=e(k) \\
& x c_{3}=e(k)-2 e(k-1)+e(k-2)
\end{aligned}
$$

the control algorithm is taken from PID output as:

$$
\Delta u(k)=k_{p} x c_{1}+k_{i} x c_{2}+k_{d} x c_{3}
$$

three parameters of PID controller used to adjust the gradient method:

$$
\begin{aligned}
& \Delta K_{p}=-\eta \frac{\partial E}{\partial k p}=\eta e(k) \frac{\partial y}{\partial \Delta u} x c_{1} \\
& \Delta K_{i}=-\eta \frac{\partial E}{\partial k i}=\eta e(k) \frac{\partial y}{\partial \Delta u} x c_{2} \\
& \Delta K_{d}=-\eta \frac{\partial E}{\partial k d}=\eta e(k) \frac{\partial y}{\partial \Delta u} x c_{3}
\end{aligned}
$$

the PID parameter increment $\Delta K p, \Delta K i, \Delta K d$ can be updated through the iteration. The parameters of PID controller $k_{p}, k_{i}, k_{d}$ can be written as:

$$
\begin{aligned}
& k_{p}(k)=k_{p}(k-1)+\Delta k_{p} \\
& k_{i}(k)=k_{i}(k-1)+\Delta k_{i} \\
& k_{d}(k)=k_{d}(k-1)+\Delta k_{d}
\end{aligned}
$$




\subsection{RBFNN metamodel based PID tuning}

Metamodelling process involves the determination of simpler model from a complex model that provides less computation or control effort. Table 2 shows the RBF metamodel parameter for both the initial dataset and the large dataset. The metamodel approach used with radial basis function neural network is summarized in the following steps:

- Select the parameters need to be optimized (i.e., PID controller parameters).

- Next, generate initial input dataset (D) with a smaller number of iterations for the PID controller parameters.

- Run the simulation in simulink (as shown in Figure 3) by using all input dataset (D) and set the target dataset $(\mathrm{T})$ from the corresponding integral square error (ISE) index values.

- Run the fitting of D and T dataset using radial basis function neural network (RBFNN).

- Evaluate RBFNN obtained in (4) using denser dataset (large dataset, D').

- Find the minimum output of the RBFNN output in (5) which corresponds to the smallest value of the ISE for large dataset.

- The equivalent PID gains that minimized the RBF output, will be the gains that will be used to simulate the maglev system, which is finally identified as the PID optimal parameters.

- The integral square error (ISE) block is connected to magnetic levitation system MLS shown in Figure 3 used to check the error, thus the process will be repeated if the output min error is not satisfied. In other word, the error gotten by metamodel RBF must be less than the one gotten by conventional PID.

Table 2. Controller parameter used for simulation

\begin{tabular}{lcc}
\hline \multicolumn{1}{c}{ Dataset } & PID Parameter & PID Gain Range \\
\hline Large data set & $\mathrm{K}_{\mathrm{i}}$ & $4: 0.1: 20$ \\
& $\mathrm{~K}_{\mathrm{p}}$ & $50: 2: 120$ \\
& $\mathrm{~K}_{\mathrm{D}}$ & $0.06: 0.01: 0.40$ \\
Total data configuration & & 202,860 \\
Initial data set & $\mathrm{K}_{\mathrm{i}}$ & $9: 0.1: 15$ \\
& $\mathrm{~K}_{\mathrm{p}}$ & $50: 2: 116$ \\
& $\mathrm{~K}_{\mathrm{D}}$ & $0.06: 0.01: 0.13$ \\
Total data configuration & & 16,592 \\
\hline
\end{tabular}

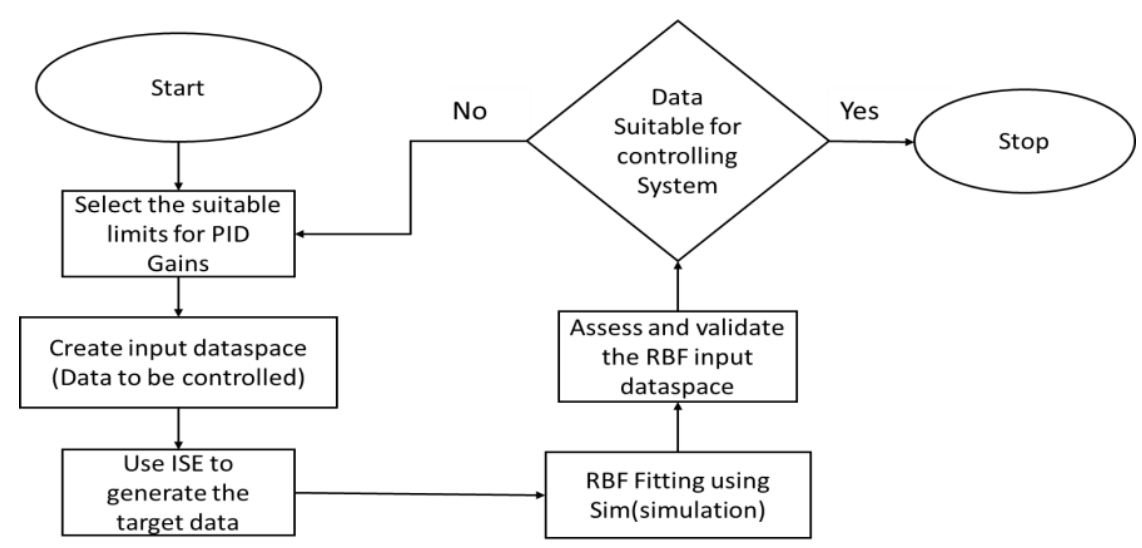

Figure 3. Overview of metamodel based RBF

\section{RESULTS AND DISCUSSION}

\subsection{RBFNN metamodel-based PID tuning performance}

The metamodeling approch intended to reduce the computation process and time process, besides produce more efficint response Figure 4 shows the magnetic levitation model implementation in Matlab/Simulink. The varying parameters of PID values (i.e., represents as inputs in RBFNN metamodel) in different sampling interval were investigated to see the resultant series of ISE values.

The RBFNN metamodel based PID tuning was used to get the best performance of maglev system by obtaining the suitable PID gains. The system response is shown in Figure 5. where the PID values used are: $k_{p}=15, k_{i}=100, k_{d}=0.1$ when the ISE during the tuning was 0.00104 . The system output characteristics are, rise time $T_{r}=9.85 \mathrm{~ms}$, overshoot $=9.34 \%$, undershoot $=0.094 \%$, settling time $T_{s}=$ 
$0.25 \mathrm{~s}$. comparing these results with the one in [3], [14]. The rise time is $0.28 \mathrm{sec}$ for two degrees of freedom controller and the settling time is $0.35 \mathrm{sec}$. also comparing $0.25 \mathrm{sec}$ settling time to [16], the best settling time they got is $0.6 \mathrm{sec}$. the results for coefficient diagram method (CDM) based PID controller in [18] shows a good overshoot, but slow settling time of 0.96 sec. Wahid et al. [24] RBF based PID controller has been used for maglev system and the results show a settling time of $0.5 \mathrm{sec}$.

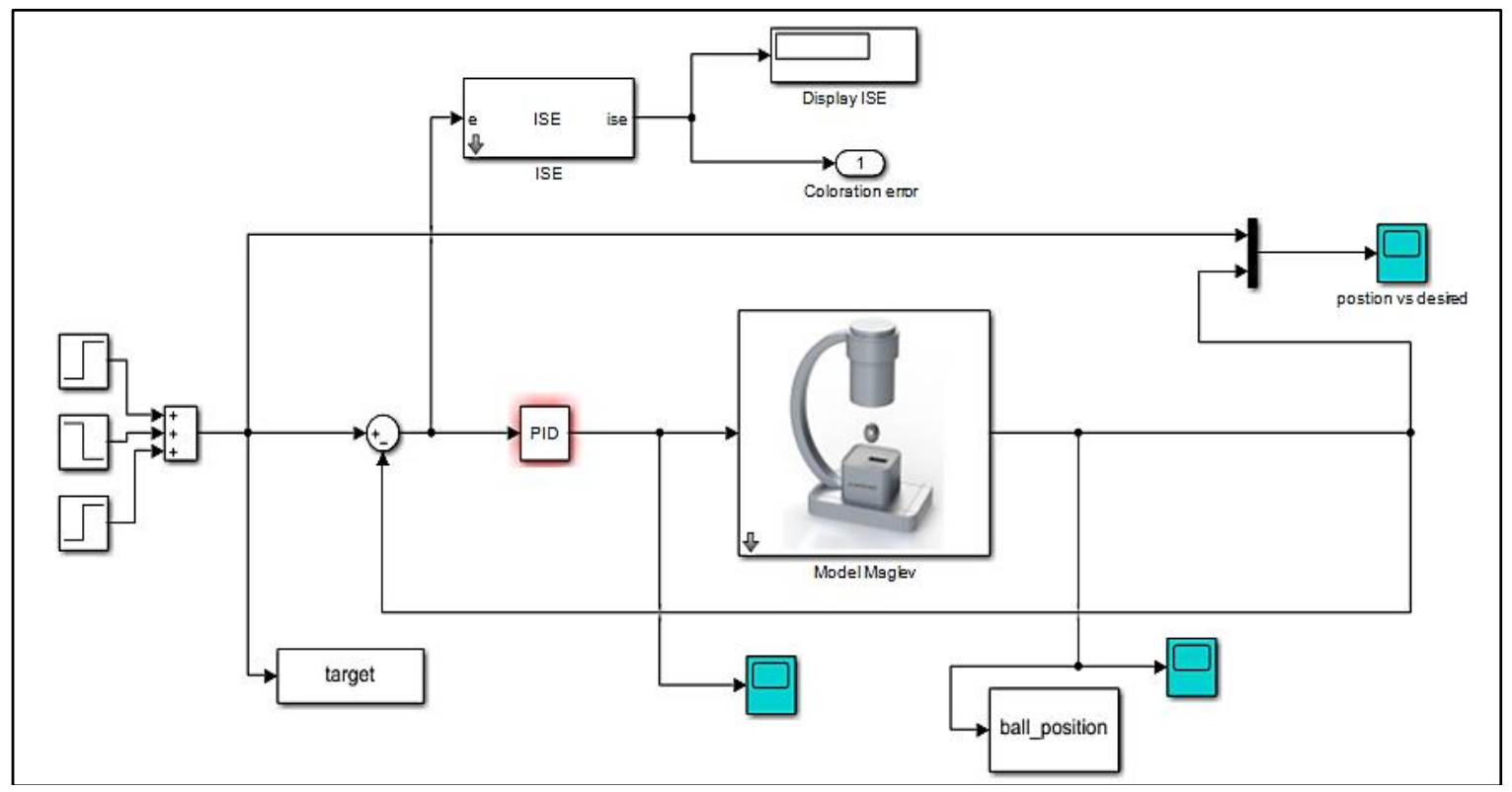

Figure 4. Maglev system based on RBFNN metamodel simulation diagram

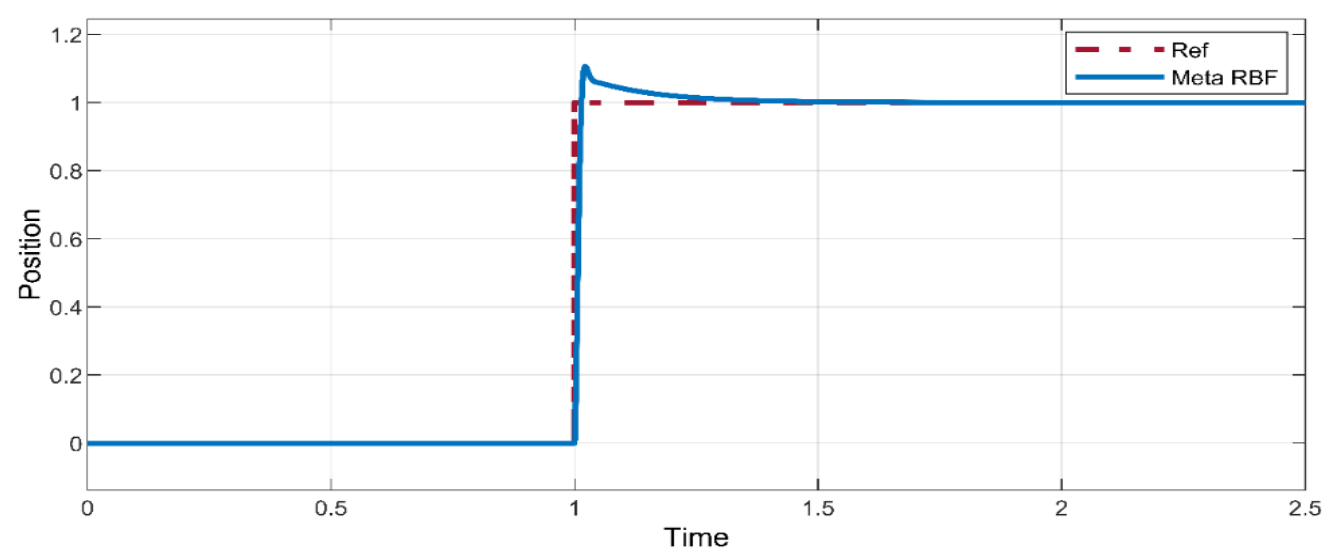

Figure 5. Response of RBFNN metamodel based PID tuning

\subsection{Gradient descent based PID tuning performance}

The gradient descent (GD) is an algorithm of optimization which is intuitive and efficacious. In many diverse electromechanical systems, the GD technique has effectively optimized the complicated system. The method used in this study to tune PID controller is the gradient descent provided by Matlab/Simulink toolbox, which called as response optimizer. The output response is shown in Figure 6. The PID parameters yield from GD optimizer are $k_{p}=7.696, k_{i}=51.34, k_{d}=0.46$. The system output after applying the PID gain it show that, rise time $T_{r}=72.92 \mathrm{~ms}$, overshoot $=21.34 \%$, undershoot $=1.91 \%$, settling time $T_{s}=0.70 \mathrm{~s}$. 


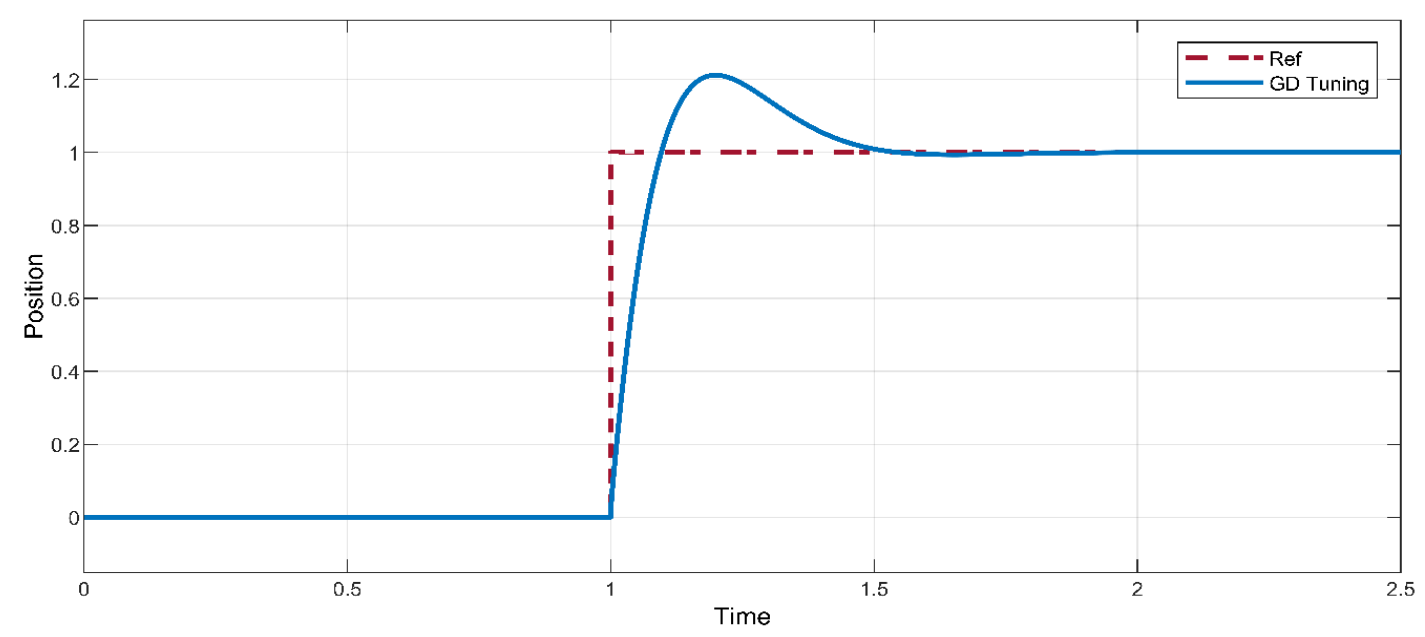

Figure 6. Response of GD Based PID Tuning

\subsection{Comparative study of tuning performance}

The maglev system response as shown in Figure 7 has three different tuning methods which are the RBFNN metamodel, gradient descent and conventional PID. Besides, the comparison data between these tuning methods are listed in Table 3. The best rise time is $9.85 \mathrm{~ms}$ and the overshoot is $9.34 \%$, which is offered by the RBFNN metamodel approach. However, the settling time performance is very close between conventional PID and RBF metamodel. The conventional PID has better results than the gradient descent method where the rise time and the overshoot are $18.45 \mathrm{~ms}$ and $19.53 \%$, respectively, thus the less successful method used to tune the PID controller in this study has been found to be produced by the GD algorithm.

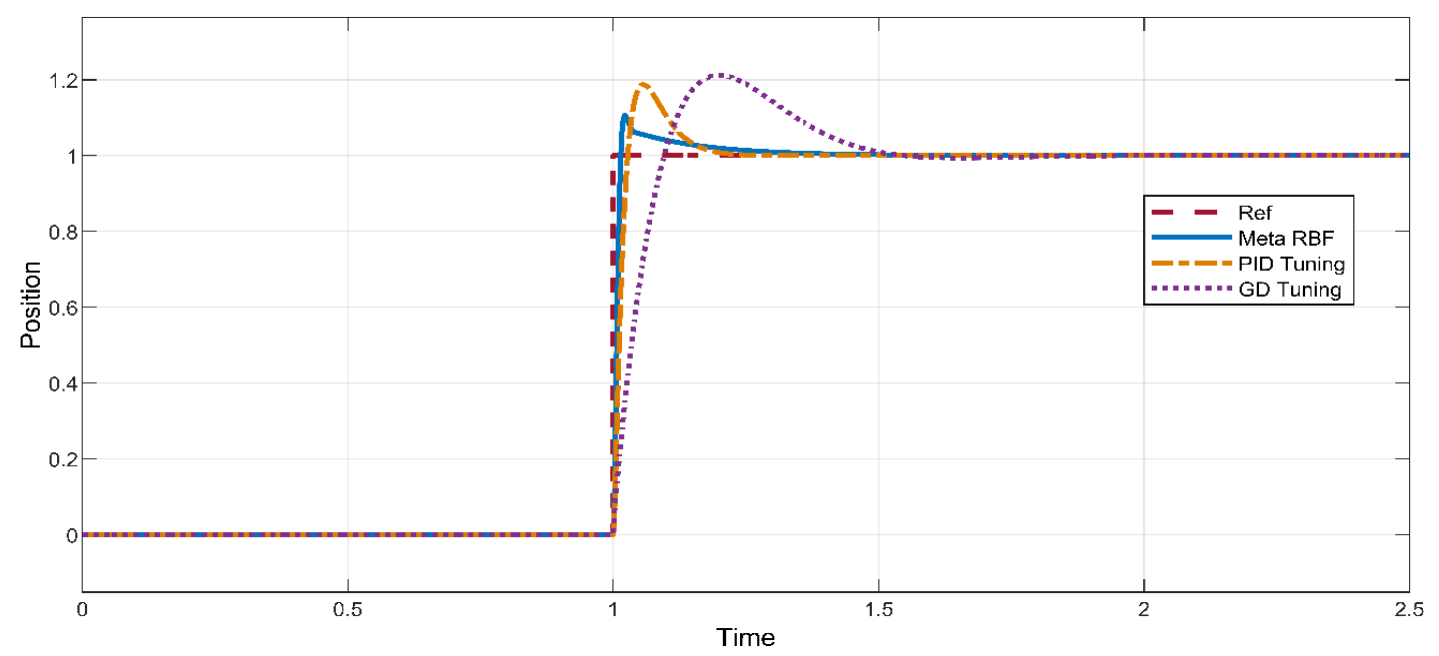

Figure 7. PID, meta-RBF and GD output response

Table 3. Performance comparison of tuning methods

\begin{tabular}{cccc}
\hline Response characteristic & Metamodel & GD & Conventional tuning \\
\hline Rise time (ms) & 9.85 & 72.92 & 19.535 \\
Overshoot (\%) & 9.34 & 21.34 & 18.45 \\
Undershoot (\%) & 0.144 & 1.919 & 1.553 \\
Settling time (s) & 0.25 & 0.70 & 0.22 \\
\hline
\end{tabular}




\subsection{Performance verification of maglev system in Simscape simulation}

Simscape multibody is a library integrated with Matlab/Simulink and uses blocks to build a 3D model that consists of joints, constraints, and force elements for instance electromagnetic force. The developed block connection of Simscape for maglev system is shown in Figure 8. After connecting all the blocks together and setting the parameters value based on the actual model, the maglev system is then linked to $3 \mathrm{D}$ animation design via solid works. There are two important components for Simscape to work, first, is a compatible software that can design 3D model and export that model to a Simscape file, and here it comes the role of solid works, where solid works computer-aided design (CAD) can design separate parts based on specific dimensions and then sample them all in one 3D model to be exported as a Simscape file. The second part is reading the Simscape file using Matlab/Simulink and define all the parts based on their functionality. The 3D design is shown in Figure 9.

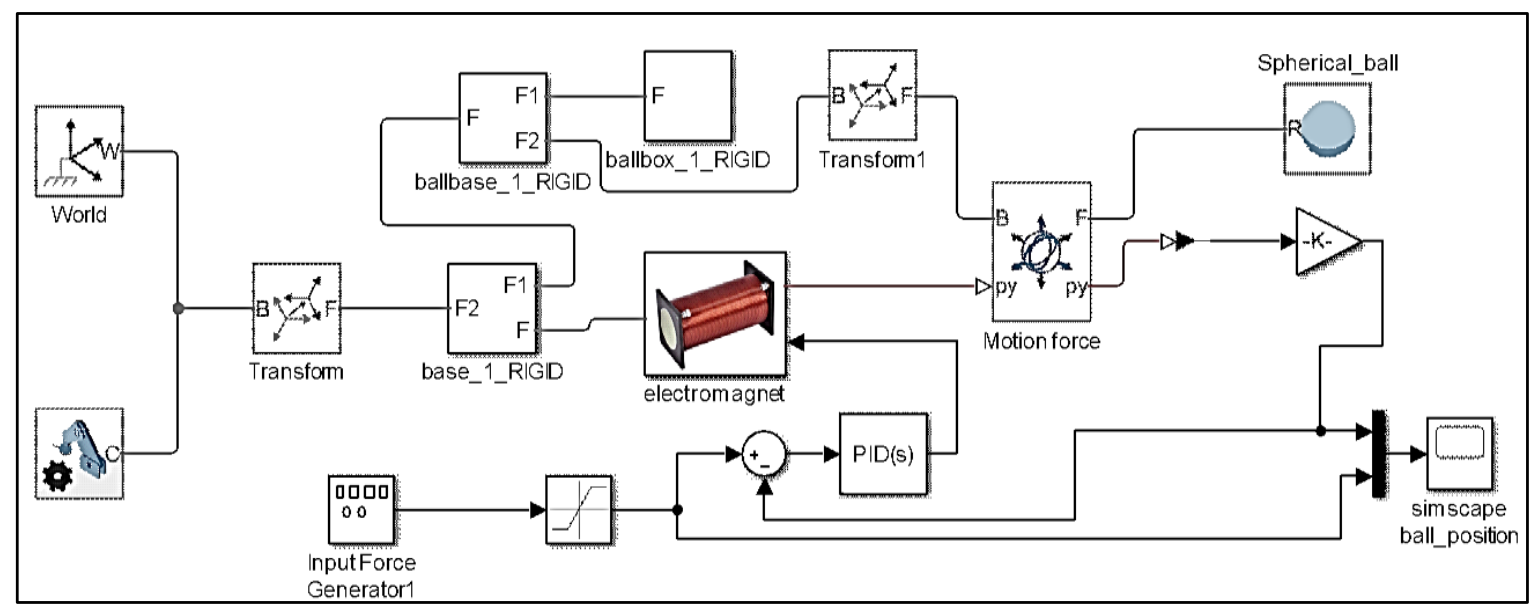

Figure 8. Simscape block diagram for MLS

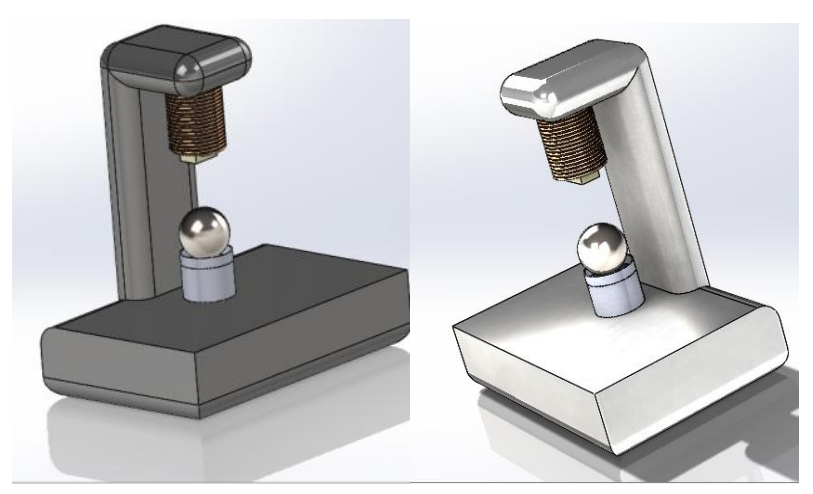

Figure 9. Maglev 3D diagram using solidworks

The values for PID parameters that were used to verify the maglev system using Simscape model are $k_{p}=15, k_{i}=100$ and $k_{d}=0.1$, which utilizes RBFNN metamodel optimal parameters, as obtained in section 4. The system output performance is depicted in Figure 10. The system produces an overshot of $13.07 \%$ and a rise time of $7.38 \mathrm{~ms}$. It is found that the performance of the simulated system (as in section 4) has better results in terms of overshoot (i.e., 9.34\%), as the previous simulation represented the ideal environment. However, for the Simscape model, we build a physical component based on physical connection which is representing a real system, hence, the system performance by using similar PID parameters yield a slightly reduced performance, especially in term of the overshoot. 


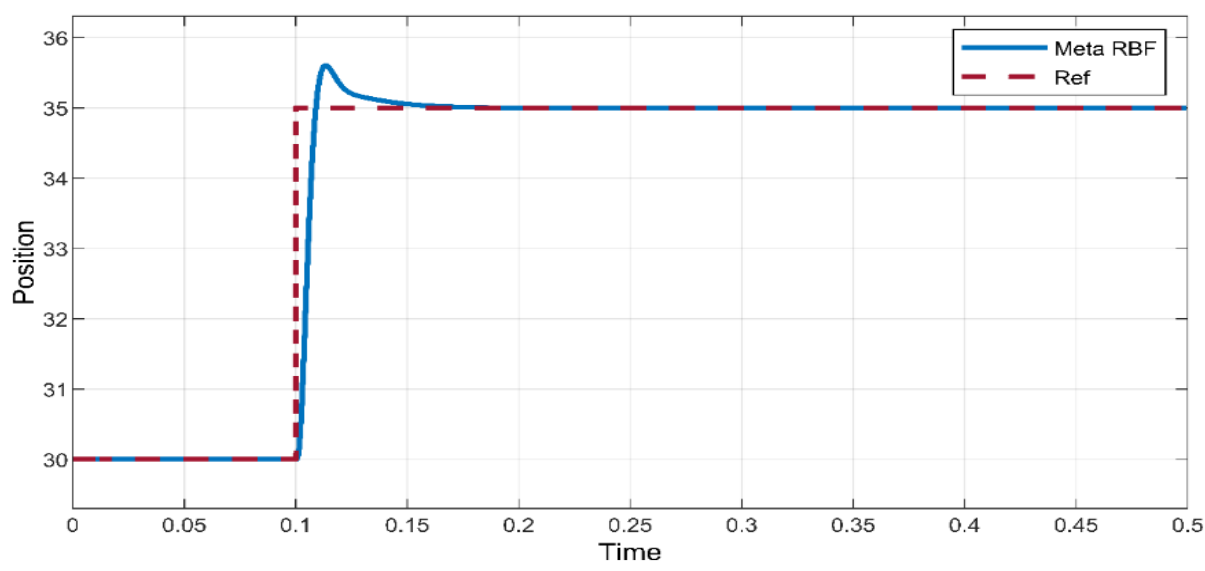

Figure 10. Output response for MLS Simscape model

\section{CONCLUSION}

This paper praises a PID tuning method using the radial basis function neural network (RBFNN) Metamodel and comparing the output results with gradient descent optimization and conventional PID methods. Furthermore, the RBF metamodel controller has been compaered with different papers that can be seen in the results section, and the compareson shows that the method used in this paper has improved the performance of settling time and overshoot between 35\% to 70\%. The metamodel based PID tuning approach showed transient response with better overshoot and rise time as compared to other optimization methods. For the trained datasets, RBF networks perform more robustly and indulgently than the GD method even when dealing with noisy input data sets. Thus, RBFNN metamodel is recommended specifically for surface with regular peaks and valleys for functional approximation issues, since effective and accurate designs are attainable. The verification using Simscape model had also shown that the tuned PID parameters using the proposed approach able to obtain about similar performance as of using Matlab simulation.

\section{ACKNOWLEDGEMENTS}

This work is funded by the Ministry of Higher Education under FRGS, Registration Proposal No: FRGS/1/2020/ICT02/UTM/02/5 \& UTM.

\section{REFERENCES}

[1] B. Bidikli, "An observer-based adaptive control design for the maglev system," Transactions of the Institute of Measurement and Control, vol. 42, no. 14, pp. 2771-2786, 2020, doi: 10.1177/0142331220932396.

[2] H. Yaghoubi, “The Most Important Maglev Applications," Journal of Engineering, 2013, doi: 10.1155/2013/537986.

[3] D. Gupta, S. K. Suman, and A. Kumar, "Control and Stabilization of Maglev System Using 2- DOF PID Controller and its Comparative Analysis with Other PID Controller," Journal of Electronic Design Technology, vol. 11, no. 2, 2020, doi: 10.37591/joedt.v11i2.416.

[4] G. R. Souza et al. "Three-dimensional tissue culture based on magnetic cell levitation," Nature Nanotech, vol. 5, pp. 291-296, 2010, doi: 10.1038/nnano.2010.23.

[5] R. Nasiri-Zarandi and A. Hekmati, "A Review of Suspension and Traction Technologies in Maglev Trains," International Power System Conference (PSC), 2019, pp. 129-135, doi: 10.1109/PSC49016.2019.9081455.

[6] P. Leng, P. Yu, M. Gao, J. Li, and Y. Li, "Optimal Control Scheme of Maglev Train Based on The Disturbance Observer," Chinese Control Conference (CCC), 2019, pp. 1935-1940, doi: 10.23919/ChiCC.2019.8866319.

[7] Z. Wang, C. Huang, X. Li, and Z. Long, "Balanced Levitation Control of PEMS High Speed Maglev Train Considering System Model Non-Symmetry," IEEE 7th Data Driven Control and Learning Systems Conference (DDCLS), 2018, pp. 216-221, doi: 10.1109/DDCLS.2018.8515937.

[8] Z. Guo, D. Zhou, Q. Chen, P. Yu, and J. Li, "Design and Analysis of a Plate Type Electrodynamic Suspension Structure for Ground High Speed Systems,” Symmetry, vol. 11, no. 9, 2019, doi: 10.3390/sym11091117.

[9] M. J. Khan, M. Junaid, S. Bilal, S. J. Siddiqi, and H. A. Khan, "Modelling, Simulation \& Control of Non-Linear Magnetic Levitation System," IEEE 21st International Multi-Topic Conference (INMIC), 2018, pp. 1-5, doi: 10.1109/INMIC.2018.8595598.

[10] A. K. Sukede and J. Arora, “Auto tuning of PID controller," International Conference on Industrial Instrumentation and Control (ICIC), 2015, pp. 1459-1462, doi: 10.1109/IIC.2015.7150979.

[11] A. Ashkarran and M. Mahmoudi, "Magnetic Levitation Systems for Disease Diagnostics," Trends in Biotechnology, vol. 39, no. 3, pp. 311-321, 2021, doi: 10.1016/j.tibtech.2020.07.010.

[12] G. Altintas and Y. Aydin, "Optimization of Fractional and Integer Order PID Parameters using Big Bang Big Crunch and Genetic Algorithms for a MAGLEV System," IFAC-PapersOnLine, vol. 50, no. 1, pp. 4881-4886, 2017, doi: 10.1016/j.ifacol.2017.08.978. 
[13] S. B. Köse, E. Yumuk, M. Güzelkaya, and İ. Eksin, “Analytical and Optimal Fractional Order Controller Design Methodologies Implemented on Magnetic Levitation System," 11th International Conference on Electrical and Electronics Engineering (ELECO), 2019, pp. 759-763, doi: 10.23919/ELECO47770.2019.8990535.

[14] D. Sain, S. K. Swain, T. Kumar, and S. K. Mishra, "Robust 2-DOF FOPID Controller Design for Maglev System Using Jaya Algorithm," IETE Journal of Research, vol. 66, no. 3, pp. 414-426, 2018, doi: 10.1080/03772063.2018.1496800.

[15] S. Kishore and V. Laxmi, "Modeling, analysis and experimental evaluation of boundary threshold limits for Maglev system," International Journal of Dynamics and Control, vol. 8, no. 3, pp. 707-716, 2020, doi: 10.1007/s40435-020-00619.

[16] S. A. Vimala and S. Sathiyavathi, "Design of sliding mode controller for magnetic levitation system," Computers \& Electrical Engineering, vol. 78, pp. 184-203, 2019, doi: 10.1016/j.compeleceng.2019.07.007.

[17] S. M. R Rasid, M. B. Hossain, M. E. Hoque, M. A. A. Arif, and M. S. Ali Sarder, "Modeling and Control of a Magnetic Levitation System Using an Analog Controller," Acta Electronica Malaysia, vol. 3, no. 2, pp. 41-44, 2019, doi: 10.26480/aem.02.2019.41.44.

[18] K. Poomani, R. Rameswari, and S. Sathiyavathi, "Implementation of CDM based PID Controller for Magnetic Ball Levitation System," 14th IEEE India Council International Conference (INDICON), 2017, pp. 1-5, doi: 10.1109/INDICON.2017.8487235.

[19] F. Isdaryani, F. Feriyonika, and R. Ferdiansyah, "Comparison of Ziegler-Nichols and Cohen Coon tuning method for magnetic levitation control system,” Journal of Physics: Conference Series, vol. 1450, 2020, doi: 10.1088/1742-6596/1450/1/012033.

[20] C. Chen, J. Xu, W. Ji, L. Rong, and G. Lin, "Sliding Mode Robust Adaptive Control of Maglev Vehicle's Nonlinear Suspension System Based on Flexible Track: Design and Experiment," in IEEE Access, vol. 7, pp. 41874-41884, 2019, doi: 10.1109/ACCESS.2019.2906245.

[21] H. Mirzaeinejad, "Robust predictive control of wheel slip in antilock braking systems based on radial basis function neural network," Applied Soft Computing, vol. 70, pp. 318-329, 2018, doi: 10.1016/j.asoc.2018.05.043.

[22] S. Slama, A. Errachdi, and M. Benrejeb, "Neural Adaptive PID and Neural Indirect Adaptive Control Switch Controller for Nonlinear MIMO Systems," Mathematical Problems in Engineering, 2019, doi: 10.1155/2019/7340392.

[23] Y. Sun, J. Xu, H. Qiang, C. Chen, and G. Lin, “Adaptive sliding mode control of maglev system based on RBF neural network minimum parameter learning method," Measurement, vol. 141, pp. 217-226, 2019, doi: 10.1016/j.measurement.2019.03.006.

[24] H. Wahid, Q. P. Ha, and M. S. Mohamed Ali, "Optimally-Tuned Cascaded PID Control using Radial Basis Function Neural Network Metamodeling," Proc. of the 3rd International Workshop on Artificial Intelligence in Science and Technology (AISAT'09), 2009.

[25] D. Ma, M. Song, P. Yu, and J. Li, "Research of RBF-PID Control in Maglev System," Symmetry, vol. 12, no. 11, 2020, doi: $10.3390 /$ sym 12111780 .

\section{BIOGRAPHIES OF AUTHORS}
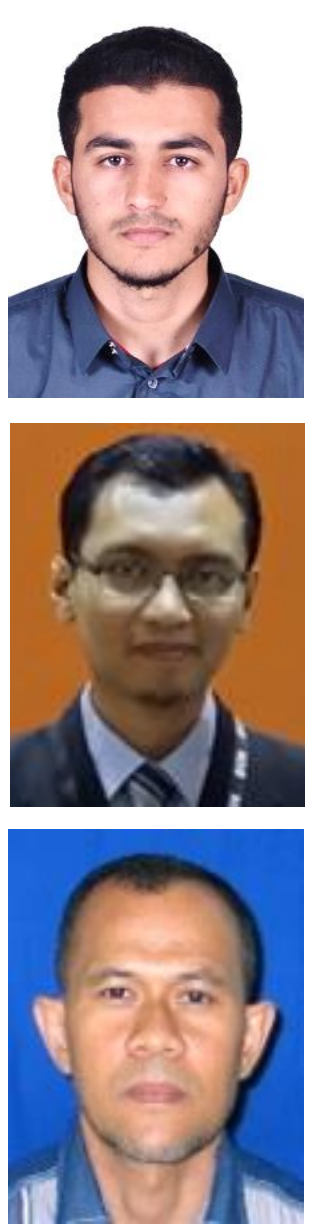

Abdualrhman Abdalhadi (iD $\mathrm{SC}$ SC is a mechatronics engineer which awarded B.Eng. in mechatronics engineering with Honours in 2018, and M.Eng in Electrical Engineering (Mechatronics and Automatic Control) in 2021 from Faculty of Electrical Engineering, Universiti Teknologi Malaysia (UTM), Malaysia. His research interest includes Automation, Robotics, Control System and Artificial Intelligence. He can be contacted at email: abdualrhman183@gmail.com.

Herman Wahid (iD 8) SC P received the B.Eng. in Electrical Engineering (Instrumentation and Control) in 2000, and M.Eng in Electrical Engineering (Mechatronics and Automatic Control) in 2007 from Faculty of Electrical Engineering, Universiti Teknologi Malaysia (UTM), Malaysia. He then obtained his Ph.D from University of Technology, Sydney (UTS), Australia in 2013. He has five years experience in industry (2000-2005) and is currently a Senior Lecturer in UTM. His research interests include artificial intelligences, controller design and optimization, environmental quality instrumentation and energy harvesting system. He can be contacted at email: herman@utm.my.

Dirman Hanafi Burhanuddin (D) $\mathrm{SC}$ P is currently working at Universiti Tun Hussein Onn Malaysia, Johor. His research interest includes Intelligent Control System System, Identification, Artificial Intelligent, Robotics. He is serving as an honorary author for Global Journal of Technology and Optimization. He has authored of several H1 research articles/books related to Control Engineering and Technology. His research interest includes Intelligent Control System, Identification, Artificial Intelligent and Robotics. He can be contacted at email: dirman@uthm.edu.my. 